\title{
Alessandra Ferraro, Anna Pia De Luca (Textes réunis et présentés par), Parcours migrants au Québec. L'italianità de Marco Micone à Philippe Poloni
}

\section{Veronica Cappellari}

\section{(2) OpenEdition}

\section{Journals}

\section{Edizione digitale}

URL: https://journals.openedition.org/studifrancesi/46399

DOI: $10.4000 /$ studifrancesi.46399

ISSN: 2421-5856

\section{Editore}

Rosenberg \& Sellier

\section{Edizione cartacea}

Data di pubblicazione: 1 octobre 2007

Paginazione: 488

ISSN: 0039-2944

\section{Notizia bibliografica digitale}

Veronica Cappellari, «Alessandra Ferraro, Anna Pia De Luca (Textes réunis et présentés par), Parcours migrants au Québec. L'ítalianità de Marco Micone à Philippe Poloni», Studi Francesi [Online], 152 (LI | II) | 2007, online dal 30 novembre 2015, consultato il 24 novembre 2021. URL: http://

journals.openedition.org/studifrancesi/46399; DOI: https://doi.org/10.4000/studifrancesi.46399

Questo documento è stato generato automaticamente il 24 novembre 2021.

\section{cc) $(9)$}

Studi Francesi è distribuita con Licenza Creative Commons Attribuzione - Non commerciale - Non opere derivate 4.0 Internazionale. 


\title{
Alessandra Ferraro, Anna Pia De Luca (Textes réunis et présentés par), Parcours migrants au Québec. L'italianità de Marco Micone à Philippe Poloni
}

\author{
Veronica Cappellari
}

\section{NOTIZIA}

ALESSANDRA FERRARO, ANNA PIA DE LUCA (Textes réunis et présentés par), Parcours migrants au Québec. L'italianità de Marco Micone à Philippe Poloni, Udine, Forum, 2006, pp. 115.

1 Parcours migrants au Québec. L'italianità de Marco Micone à Philippe Poloni raccoglie gli interventi dedicati a opere letterarie, cinematografiche, musicali e artistiche del Canada presentati in occasione del convegno internazionale "Oltre la storia. Beyond History. Au delà de l'histoire: l'identità italo-canadese contemporanea" tenutosi a Udine nel maggio 2004. Il volume, suddiviso in due sezioni rispettivamente intitolate «L'italianità dans les œuvres littéraires» e «L'immigration italienne: aspects artistiques et linguistiques», si apre con un articolo di Marco MICONE, L'italianità: une voie vers l'universel, nel quale l'autore delinea la storia dell'immigrazione italiana in Québec, soffermandosi poi, più in particolare, sulla propria nozione di culture immigrée, secondo la quale il migrante si inserisce nella comunità di adozione senza tuttavia negare il proprio passato e le proprie radici.

2 L'opera di Micone è oggetto di ben quattro comunicazioni: Pierre L'HÉRAULT in Entre essai et autofiction: l'indécision générique dans l'écriture de Marco Micone sottolinea quanto sia presente la dimensione autobiografica nelle opere dello scrittore di origine italiana, mentre in Le "plus que français» ou la représentation de la langue italienne dans "Trilogia" de 
Marco Micone, Jean-Pauf DUfIET descrive il modo in cui l'autore porta sulla scena la propria lingua madre attraverso l'invenzione linguistica del «plus que français». Katalin KÜRTÖSI, in References to History and Stereotyping Italian Characters in Canadian Plays, propone, invece, un parallelo tra la pièce Babel di Micone e Even Loving della drammaturga canadese anglofona Margaret Hollingswhort, facendone soprattutto risaltare l'affinità nella raffigurazione degli stereotipi dell'italianità, mentre Stefania CUBEDDU, in "Questa sera si recita a soggetto". Le théâtre des Italiens de Montréal presenta un'analisi particolareggiata della raccolta Trilogia.

3 Se la difficile esperienza dell'immigrazione e della successiva integrazione nella nuova società è tema principale della produzione miconiana, negli scrittori italo-quebecchesi delle generazioni successive il rapporto con l'italianità, e la sua rappresentazione in campo letterario, subisce notevoli mutamenti determinati, principalmente, dal diverso legame che essi hanno avuto con la realtà italiana. In La malédiction de l'italianità dans "Impala" de Carole David Élisabeth NARDOUT-LAFARGE osserva per l'appunto come, in questo romanzo, l'italianità venga raffigurata in modo oscuro, ai limiti dell'ignoto; in Bianca Zagolin et Philippe Poloni: de l'exil de soi à la recherche des origines, Elena MARCHESE analizza e confronta, invece, i romanzi di due autori originari del Friuli: Une femme à la fenêtre di Bianca Zagolin (dove l'esperienza dell'immigrazione viene rappresenta in maniera dolorosa e drammatica), e Olivo Oliva di Philippe Poloni, nel quale lo status di esule viene ritratto in chiave piuttosto ironica; Mirko CASAGRANDE, infine, focalizza il suo intervento sul concetto di culture italique coniato da Antonio D'Alfonso nel suo saggio In Italics: in Defense of Ethnicity, con il quale si vuol sottolineare la complessa identità dell'esule.

4 La seconda parte del volume raggruppa gli studi di Anna CARLEVARIS (In the Shadow of my Hero. Guido Nincheri's Painting in Madonna della Difesa, Montréal) e di Sherry Simon (Guido Nincheri et l'église Saint Michael's du Mile-End) dedicati a Guido Nincheri, artista fiorentino che agli inizi del xIx secolo affrescò numerose chiese di Montréal, e un articolo di Valeria zотті (Quel lexique québécois dans un dictionnaire général bilingue italien-français? Essai de description et d'aménagement) sulla creazione di un dizionario italiano-francese che tenga anche conto degli apporti linguistici quebecchesi. Grazie alla ricchezza e alla puntualità degli interventi, Parcours migrants au Québec costituisce sicuramente una lettura fondamentale per comprendere i diversi e mutevoli aspetti dell'identità dell'esule nel Canada anglofono e in Québec, nonché una considerevole fonte di informazione e di approfondimento sui molteplici aspetti della letteratura allofona canadese. 